\title{
ANALYSIS OF MAXIMUM BITING FORCE USING GNATHODYNAMOMETER IN DIFFERENT AGE GROUPS
}

\author{
Shushma $G^{1}$, Ramalingeshwara Kantly² \\ ${ }^{1}$ Resident, Department of Dentistry, Koppal Institute of Medical Sciences, Koppal. \\ ${ }^{2}$ Assistant Professor, Department of General Surgery, Koppal Institute of Medical Sciences, Koppal.
}

\section{ABSTRACT}

\section{BACKGROUND}

Mastication is directly related with maximum bite force, which is nothing but maximum biting force of individual during chewing food and is influenced by many factors. The main objective of this study is to analyse maximum biting force of subjects in varying age groups.

\section{MATERIALS AND METHODS}

One hundred individuals were equally divided according to age groups and gender. Anthropometric measurements of height and weight is done to each individual to get body mass index using tape and digital scale. Then maximum bite force of each individual is measured using Gnathodynamometer (bite force recorder) in Newton Scale.

Analysis of Variance was used with maximum bite force as a dependant variable, age group and gender as random factors and body mass index as control variable.

\section{RESULTS}

There was a decrease in maximum bite force in both sexes with male force greater than female force till the end of adolescence age. In young adults female force became greater than males, then decreased in adulthood. There was no correlation between MBF and BMI was found.

\section{CONCLUSION}

According to age groups, there are maximum bite force variations that characterises the human development stages.

\section{KEYWORDS}

Bite Force, Age Groups, Gnathodynamometer, Body Mass Index, Mastication.

HOW TO CITE THIS ARTICLE: Shushma G, Kantly R. Analysis of maximum biting force using gnathodynamometer in different age groups. J. Evolution Med. Dent. Sci. 2016;5(100):7323-7326, DOI: 10.14260/Jemds/2016/1658

\section{BACKGROUND}

The masticatory function is acquired by eating experiences and is especially influenced by the consistencies of food. The Maximum Bite Force (MBF), based on masticatory function and related to individual anthropometric characteristics such as sex and age has been discussed in the literature.(1,2) The MBF varies according to gender, general physical structure (height and weight), condition of teeth, facial morphology and also age.(2,3) There are some contradictions in the literature on the real relationship between these variables.(4-7)

There are several factors that can influence MBF like the condition of the dentition, the strength of the jaw-closing muscles and the pain threshold of the subject.(8) Bite force varies within the regions of the oral cavity and is greatest in the first molar area.(8) It is also likely that the degree of jaw opening and hence muscle length is important in influencing maximum bite force.

Financial or Other, Competing Interest: None.

Submission 09-11-2016, Peer Review 03-12-2016,

Acceptance 09-12-2016, Published 15-12-2016.

Corresponding Author:

Dr. Shushma G,

Resident.

Department of Dentistry,

KIMS, Koppal.

E-mail: kantlybmc@gmail.com

DOI: $10.14260 /$ jemds/2016/1658
MBF also varies in different age groups. It is greater in adults with a rectangular craniofacial morphology and skeletal deep bite than in those who have a long face and open bite.(9) It is also possible that signs and symptoms of temporomandibular dysfunctions can interfere with correct masticatory function and muscle strength in children(10) as well as in adults.(11)

Masticatory performance has been shown to be decreased in subjects with malocclusions when compared with those with a normal occlusion.(12) With regard to general muscle strength, this has been shown to be as strong and as large in females as in males until puberty. It is believed that genderrelated bite force differences develop during the post-pubertal period in association with greater muscle development influenced by androgenic steroids in males $(13,14)$ and that a decline in occlusal force is associated with masticatory performance with ageing.(15)

Some investigations have established the influence of age and gender on MVBF,(16) while others investigated the association of MBF with weight, height and body mass index.(17) The aim of this study was to analyse the MBF according to different age groups, gender and Body Mass Index (BMI).

\section{MATERIALS AND METHODS}

This study was done in Koppal District Hospital attached to KIMS, Koppal. The study sample consisting 100 subjects of different age groups between 10 and 60 [Table 01].

The inclusion criteria of the sample were as follows: be at least 11 years old for female participants and at least 12 years 
for male participants with a maximum age restriction of 60 years and have complete permanent dentition and absence of dental mutilation, regardless of the type of dental occlusion. Individuals of age groups described in the above classification. The exclusion criteria of the sample were as follows: the age groups described in the literature as infancy, because it involves individuals with incomplete deciduous or mixed dentition and senility age involving individuals without teeth, in most cases not fitting one of certain basic criteria for sample. Also, considered ineligible were individuals with any kind of syndrome, degenerative diseases, mental deficiencies, malformation, changes of the temporomandibular articulation, open and cross-bite, myofunctional changes of masticatory muscles and dental implants.

The anamnesis consisted of personal information such as name, date of birth, age, gender, address and personal e-mail. Anthropometric measurements were performed with a tape measure measuring the height (in centimetres) and a digital weighing scale in kilograms. From these measurements, BMI was determined by the formula BMI $=$ weight $(\mathrm{kg}) /$ height $^{2}(\mathrm{~m})$. All the measurements were conducted by one examiner. Subsequently, dental conditions were assessed and to measure the MBF, the device Gnathodynamometer was alternately placed on the first molars and on both sides of the dental arch. Participants were instructed to bite "as hard as they could." Then, three measurements on each side were made with an interval of 2 minutes [Figure 2]. The MBF was recorded in Newtons and measured as the peak force shown on the device screen. Results were recorded in the registry of each participant for further analysis.

The collected data were analysed by analysis of variance. SPSS software was used and the test was set up to analyse the MBF as the dependent variable and with age and gender as random factors and BMI as a control variable. The confidence interval was $95 \%(\alpha=0.05)$.

\section{RESULTS}

Data analysis revealed that the measures of MBF in between $\mathrm{BMI}$, age and sex groups varied equally in large scale causing a non-rejection of the null hypothesis: the average values of MBF according to the measures listed above varied largely, but in the same proportion in all groups of analysis [Table 2]. The differences were not statistically significant between the values of MBF and age groups even without the age-gender interaction. Thus, age does not determine the MBF. After calculating the BMI, no significant relationship was found in the variables of height and weight with the MBF. The gender factor also did not significantly determine the MBF.

The mean values showed a nonlinear variation, especially in female participants for whom the values became smaller between 11 and 17 years and then rose again with another valley in early adulthood, 25 years of age [Fig. 1].

Male participants had higher values for MBF compared with girls in the pubescent period. Bite force also declined between 12 and 19 years of age. However, it appeared to be lower than that of women aged 20 years old. This difference decreases from the age of 25 , since the force for the male participants increases less abruptly as shown in [Table 3], approaching the average for female participants. After independent analysis of the age variable, the average bite force of male participants was greater than that of female participants with a difference of $31.01 \mathrm{~N}$ (male: $305.01 \mathrm{~N}$; female: $273.99 \mathrm{~N}$ ). Although, men had a bite force $12.21 \%$ higher than women, the difference was not statistically significant $(p>0.05)$.

\begin{tabular}{|c|c|c|c|c|}
\hline \multirow{2}{*}{ Age Group } & \multicolumn{2}{|c|}{ Male } & \multicolumn{2}{c|}{ Female } \\
\cline { 2 - 5 } & Age (Years) & N & Age (Years) & N \\
\hline Prepubescent & $12-13.9$ & 10 & $11-12.9$ & 10 \\
\hline Pubescent & $14-15.9$ & 10 & $13-14.9$ & 10 \\
\hline Post-Pubescent & $16-19.9$ & 10 & $15-17.9$ & 10 \\
\hline Young Adult & $20-24.9$ & 10 & $18-24.9$ & 10 \\
\hline Adult & $25-60$ & 10 & $25-60$ & 10 \\
\hline \multicolumn{4}{|c}{ Table 1. Age Group Distribution } \\
\hline
\end{tabular}

\begin{tabular}{|c|c|c|c|c|c|}
\hline Variables & $\begin{array}{c}\text { Type 3 } \\
\text { Sum of } \\
\text { Squares }\end{array}$ & df & $\begin{array}{c}\text { Square } \\
\text { Mean }\end{array}$ & F & $\begin{array}{c}\text { P } \\
\text { Value }\end{array}$ \\
\hline Intercept & 68.185 & 1 & 68.185 & 3.973 & 0.05 \\
\hline BMI & 22.586 & 1 & 22.586 & 1.252 & 0.266 \\
\hline $\begin{array}{c}\text { Age } \\
\text { Group }\end{array}$ & 152.687 & 4 & 38.156 & 1.350 & 0.394 \\
\hline Sex & 12.549 & 1 & 12.549 & 0.465 & 0.465 \\
\hline $\begin{array}{c}\text { Group* } \\
\text { Sex }\end{array}$ & 120.250 & 4 & 30.040 & 1.710 & 0.154 \\
\hline \multicolumn{7}{|c|}{ Table 2. Statistical Analysis of Data } \\
\hline
\end{tabular}

Abbreviations: df, degrees of freedom; BMI, Body Mass Index; Group *sex, interaction between the two variables.

\begin{tabular}{|c|c|c|c|c|}
\hline \multirow{2}{*}{ Age Group } & \multicolumn{2}{|c|}{ Male } & \multicolumn{2}{c|}{ Female } \\
\cline { 2 - 5 } & N & SD & N & SD \\
\hline Prepubescent & 365.01 & 134.25 & 250.58 & 85.62 \\
\hline Pubescent & 295.52 & 157.51 & 230.52 & 194.35 \\
\hline Post-Pubescent & 250.12 & 88.52 & 149.25 & 70.75 \\
\hline Young Adult & 272.28 & 99.25 & 320.56 & 60.37 \\
\hline Adult & 290.58 & 230.25 & 310.96 & 99.56 \\
\hline $\begin{array}{c}\text { Independent of } \\
\text { Age Group }\end{array}$ & 286.25 & 150.17 & 250.36 & 132.52 \\
\hline Table 3. Means of MBF in Newtons and Standard \\
Deviations for Each Age Group \\
\hline
\end{tabular}

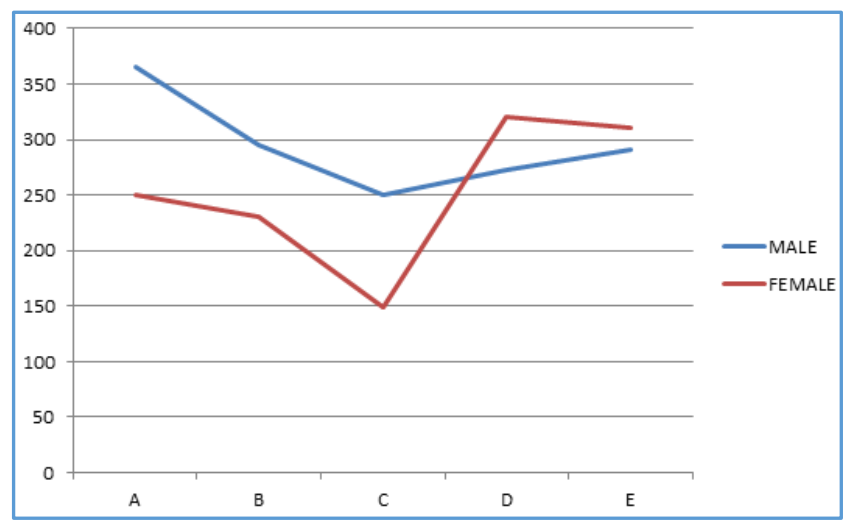

Figure 1. Variation of MBF (Means) in Different Age Group 


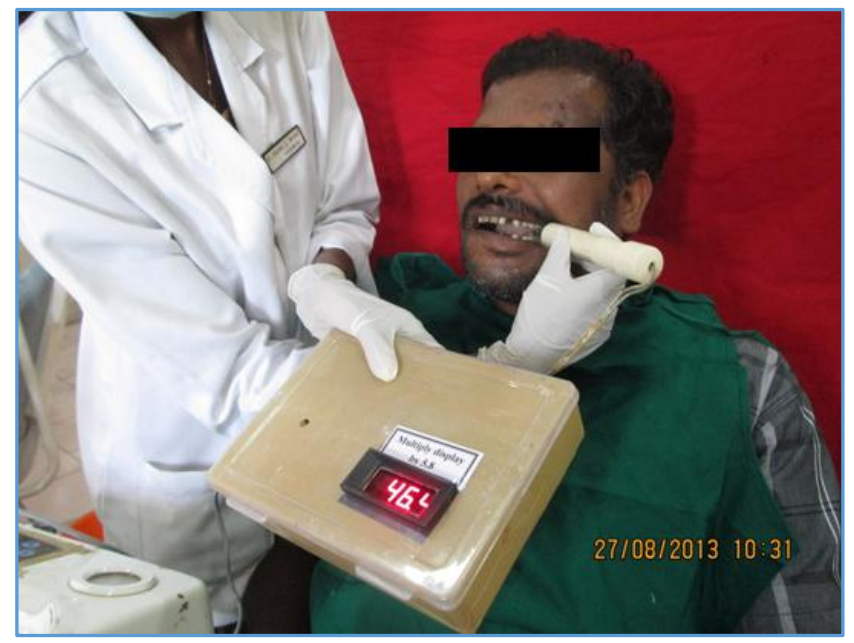

Figure 2. Measuring MBF using Gnathodynamometer

\section{DISCUSSION}

MBF seems to provide useful information for objective evaluation of occlusion,(16) but few studies have primarily been based on subjects without morphological and functional occlusal disturbances. Shinogaya et al (1999) reported that 80 percent of total bite force is distributed in the molar area. Therefore, in the present investigation, MBF was measured in the first permanent molar region and the subjects were selected according to strict inclusion criteria.

The occlusal force gauge used in this study, the Gnathodynamometer that provide safe, accurate, and comfortable MBF recording. Multiple recordings were recorded and to avoid random error the mean of MBF was used for data analysing. Fig. 1 shows the MBF curve in Newtons according to age groups.

Table 3 shows that there was an increase in MBF according to age. In the literature, the increase in MBF occurs in individuals between 15 and 18 years of age. Also in Table 3 , the average bite force for men was $12.21 \%$ higher than that of women with a difference of $31.01 \mathrm{~N}$ between them. Although, the results showed no statistically significant difference between the variables, there may be a greater tendency with a larger sample. In the literature, there are significant differences in MBF between men and women. A survey revealed that the bite force of men is usually $30 \%$ higher when compared with women. ${ }^{(18)}$

One study looked at the average curve between genders and stated that there is a variation of MBF according to age. However, other studies have analysed that MBF is not determined by age, but gender has been a highly correlated variable. $(5,6)$ One possible explanation for the fact that women had higher measures than men in adulthood is that the variation of responses are higher than age. Table 3 shows that the standard deviations for these groups is higher, which means that the values varied widely. Table 3 shows that MBF increased until age 20, stabilised up to 40 or 50 years of age and then a reduction occurred. As observed in this study, female participants aged over 25 years showed decreased MBF.

Some studies reported that MBF decrease with increasing age may occur mainly due to tooth decay(7) and reduced androgenic hormones,(2) which decreases in both sexes around 35 years of age. In women this decrease is more notable because they begin with a much lower rate of hormone than men, so their strength reduces more quickly.

Significant relationships were observed with BMI and MBF as a trend as found in the literature [Table 2], but one difference might be in the size of the sample. Some studies showed a non-existent relationship between MBF and body measurements.(19) Researchers studied normal subjects with permanent dentition and concluded that there is relationship between MBF and age as well as height and weight(6) and the present study found a trend [Table 2].

There is some controversy in the literature about the masticatory performance. A study of children and adolescents reported that masticatory performance increases with age ${ }^{(20)}$; another study reported that in adolescents and adults age does not influence masticatory performance.(21) Additionally, dentition is indirectly related to the $\mathrm{MBF},(20,21)$ which indicates that the force is determined by the development.

This study has limitations such as sample size, which affected the determination of the correlation between MBF and age groups as well as the influence of BMI and gender. Therefore, future research is suggested with a larger sample size. Future research is proposed to determine other variables that can directly interfere with the results, such as ethnic factor indirectly related to facial morphology, hormone levels associated with pregnancy, testosterone levels, tooth decay and masticatory preference side.

\section{CONCLUSION}

1. MBF varies qualitatively along the human development process.

2. There is an important increase in bite force in women until adulthood, which then decreases in adulthood (25 years).

3. For men, the MBF is greater than in women independent of age groups.

4. Trend was found between MBF and BMI, but it requires further analytical study.

\section{REFERENCES}

1. Bakke M. Bite force and occlusion. Semin Orthod 2006;12(2):120-6.

2. Bonjardim LR, Gavião MB, Pereira LJ, et al. Bite force determination in adolescents with and without temporomandibular dysfunction. J Oral Rehabil 2005;32(8):577-83.

3. Roldán S, Buschang PH, Saldarriaga IJF, et al. Reliability of maximum bite force measurements in age-varying populations. J Oral Rehabil 2009;36(11):801-7.

4. Varga S, Spalj S, Varga LM, et al. Maximum voluntary molar bite force in subjects with normal occlusion. Eur J Orthod 2011;33(4):427-33.

5. Kogawa EM, Calderon PS, Lauris JR, et al. Evaluation of maximal bite force in temporomandibular disorders patients. J Oral Rehabil 2006;33(8):559-65.

6. van der Bilt A, Tekamp A, van der Glas $\mathrm{H}$, et al. Bite force and electromyograpy during maximum unilateral and bilateral clenching. Eur J Oral Sci 2008;116(3):217-22.

7. Pereira LJ, Pastore MG, Bonjardim LR, et al. Molar bite force and its correlation with signs of temporomandibular dysfunction in mixed and permanent dentition. J Oral Rehabil 2007;34(10):759-66. 
8. Tortopidis D, Lyons MF, Baxendale RH, et al. The variability of bite force measurement between sessions, in different positions within the dental arch. Journal of Oral Rehabilitation 1998;25(9):681-6.

9. Alhaija AES, Al Zo'ubi IA, Al Rousan ME, et al. Maximal occlusal bite forces in Jordanian individuals with different dentofacial vertical skeletal patterns. European Journal of Orthodontics 2010;32(1):71-7.

10. Gaviao MBD, Lemos A, Serra DM, et al. Masticatory performance and bite force in relation to signs and symptoms of temporomandibular disorders in children. Minerva Stomatologica 2006;55(10):529-39.

11. Kogawa EM, Calderon PS, Lauris JRP, et al. Evaluation of maximal bite force in temporomandibular disorders patients. Journal of Oral Rehabilitation 2006;33(8):55965.

12. Tsai HH. Maximum bite force and related dental status in children with deciduous dentition. Journal of Clinical Pediatric Dentistry 2004;28(2):139-42.

13. Kiliaridis S, Kjellberg $H$, Wenneberg $B$, et al. The relationship between maximal bite force, bite force endurance, and facial morphology during growth. A crosssectional study. Acta Odontologica Scandinavica 1993;51(5):323-31.

14. Braun S, Hnat WP, Freudenthaler JW, et al. A study of maximum bite force during growth and development. Angle Orthodontist 1996;66(4):261-4.
15. Ikebe $\mathrm{K}$, Matsuda $\mathrm{K}$, Morii $\mathrm{K}$, et al. Association of masticatory performance with age, posterior occlusal contacts, occlusal force, and salivary flow in older adults. International Journal of Prosthodontics 2006;19(5):47581.

16. Shinogaya T, Sodeyama A, Matsumoto M. Bite force and occlusal load distribution in normal complete dentitions of young adults. European Journal of Prosthodontics and Restorative Dentistry 1999;7(2):65-70.

17. Castelo PM, Gaviao DMB, Pereira LJ, et al. Masticatory muscle thickness, bite force, and occlusal contacts in young children with unilateral posterior crossbite. European Journal of Orthodontics 2007;29(2):149-56.

18. Palinkas M, Nassar MS, Cecílio FA, et al. Age and gender influence on maximal bite force and masticatory muscles thickness. Arch Oral Biol 2010;55(10):797-802.

19. Lujan-Climent M, Martinez-Gomis J, Palau S, et al. Influence of static and dynamic occlusal characteristics and muscle force on masticatory performance in dentate adults. Eur J Oral Sci 2008;116(3):229-36.

20. Toro A, Buschang PH, Throckmorton G, et al. Masticatory performance in children and adolescents with Class I and II malocclusions. Eur J Orthod 2006;28(2):112-9.

21. Fontijn-Tekamp FA, van der Bilt A, Abbink JH, et al. Swallowing threshold and masticatory performance in dentate adults. Physiol Behav 2004;83(3):431-6. 